\title{
Los reinos de la naturaleza en la prensa infantil de México, 1870-1878
}

\section{The kingdoms of Natural History in Mexican press for childen, 1870-1878}

RODRIGO VEGA Y ORTEGA

Universidad Nacional Autónoma de México | UNAM

\begin{abstract}
RESUMEN La década de 1870 es relevante para la Historia de la ciencia mexicana, ya que fue el momento en que hubo un aumento en los proyectos encaminados a llevar la ciencia a todos los grupos sociales que componían la nación mexicana. Bajo esta pauta, las revistas para niños fueron medios de comunicación imprescindibles en la divulgación del conocimiento científico, como la Historia natural, acorde con lo que se aprendía en las escuelas primarias. Así, numerosos infantes mexicanos pertenecientes a las clases media y alta tuvieron a su disposición una nutrida prensa infantil que puso a su alcance tópicos naturalistas como Zoología, Botánica, Mineralogía, Paleontología y Microbiología.
\end{abstract}

Palabras clave Ciencias Biológicas - divulgación científica - infancia - prensa - Historia de la Ciencia

RESUMO The decade of 1870 is very important to the history of Mexican science since there was a significant number of projects which aimed taking science to all social groups. In that way, children magazines were indispensable to the diffusion of scientific knowledge, i. e. Natural History, in accordance to what they were learning at primary schools. Therefore, many Mexican children - from upper and middle classes - had at their disposal a large press dealing with Zoology, Botany, Mineralogy, Palaeontology and Microbiology.

Palavras-chave life science - popular science - childhood - magazines - history of science.

Durante el último tercio del siglo XIX la divulgación de las disciplinas científicas a través de la prensa mexicana amplió el grupo de lectores, entre los que destacan los niños. Lo anterior fue una tendencia iniciada décadas atrás, especialmente en las revistas para adultos que aún no se han estudiado de manera profunda. Particularmente, en la década de 1870 hubo una variedad de revistas infantiles que incluyeron contenidos científicos como El Obrero del Porvenir (1870); La Enseñanza (1870-1876); El Correo de los Niños (1872-1883); El Escolar (1872); La Edad Feliz (1873) y La Niñez Ilustrada (1873-1875). Si bien estos títulos han sido abordados por varios historiadores de la infancia como Lucía Martínez, Óscar Reyes, Mílada Bazant, Beatriz Alcubierre, Alberto Ramírez, Federico Lazarín, Laura Herrera, Anel Pérez, Alberto del Castillo y Luz Elena Galván, ninguno de ellos ha estudiado de manera amplia la presencia de las ciencias en dichas revistas. Además, los historiadores de la ciencia mexicana han privilegiado durante mucho tiempo el estudio de las revistas científicas mexicanas del último tercio del siglo XIX, por ejemplo Luz Fernanda Azuela, Consuelo Cuevas, Ana María Carrillo, Patricia Gómez, Claudia Agostoni, entre muchos otros, dejando de lado la popularización científica en la 
prensa dirigida al gran público. Fuera de México destacan algunos estudios históricos acerca de la divulgación científica y del papel de los medios de comunicación en ésta, como los encaminados por David Knight, Gowan Dawson, Nick Jardine, Geoffrey Cantor, Richard Noakes, Emma Spary, Jean Marc Drouinand, James Secord, Bernadette BensaudeVincent, Bernard Ligthman, Ann Shteir y Aileen Fyfe, quienes abordan cuestiones europeas y estadounidenses.

Por lo anterior, el objetivo de la presente investigación consiste en analizar escritos representativos de la Historia natural publicados en dichas revistas infantiles y su relación con el grupo lector al cual se dirigieron. Éste formó parte de las clases media y alta de la sociedad mexicana que tuvieron como preocupación fundamental, hacia el último tercio del siglo XIX, la educación de nuevas generaciones de acuerdo con las pautas de "orden y progreso" pregonadas por el régimen liberal en sus distintas administraciones cuya base era la ciencia práctica. En efecto, se creía que sólo bajo estos cánones era posible construir una sociedad moderna a la altura de las naciones "cultas" de Europa. ${ }^{2}$ Por ello, resultaba imprescindible formar una ciudadanía que encajara con dichos anhelos sociales.

Es necesario señalar que el decenio de 1870 marca un momento histórico particular, pues en estos años quedó definida la supremacía del Estado frente a la Iglesia católica y cualquier otra corporación civil; se pusieron los cimientos para la paz social; se intensificó el desarrollo de las vías de comunicación y de transporte a través del ferrocarril y el telégrafo; se consolidó el triunfo de las creencias liberales en términos políticos; se adoptó el positivismo en la práctica científica como parte de la noción de que ésta sería generadora de prosperidad económica; y se intensificó el proceso de profesionalización de las ciencias mexicanas, especialmente de la Historia natural.

En efecto, las revistas infantiles mencionadas tienen como marco histórico el triunfo de los liberales mexicanos frente al grupo conservador que apoyó la Intervención francesa (1862-1863) y el Segundo Imperio Mexicano (18641867). Desde entonces, los sucesivos gobiernos federales estuvieron en manos de políticos liberales, empezando por Benito Juárez (1867-1872) y seguido por Sebastián Lerdo de Tejada (1872-1876), José María Iglesias (1876-1877) y Porfirio Díaz (1877-1880), quien cierra el periodo de estudio.

A partir de 1867, Juárez inició su mandato "con una serie de acciones en las que se observa un franco apoyo a la actividad científica que fueron posteriormente consolidadas por Lerdo de Tejada". ${ }^{3}$ En efecto, los científicos fueron convocados para su inserción en el aparato gubernamental, donde el Estado se encargaría de mejorar su estatus social y laboral. Las instituciones y sociedades científicas que lograron cierta duración fueron aquellas que apoyó el gobierno o las que ya tenían un poder gremial bien establecido desde tiempo atrás. Además, los gobiernos liberales dejaron en manos de la Secretaría de Fomento el apoyo al desarrollo científico. En esta dependencia gubernamental se determinaron los objetivos generales de la práctica científica estatal, especialmente las Ciencias Naturales. ${ }^{4}$ Asimismo, este brazo del Estado fue un instrumento político para aplicar las creencias liberales y positivistas dentro de la práctica científica mexicana encargada de la política sanitaria, la exploración territorial y el estudio de la diversidad natural del país. Desde entonces, el Estado mexicano participó activamente en el desarrollo de la Historia natural, pues condicionó mucho de su apoyo a encontrar las mejores vías para explotar los recursos naturales en todas las regiones. Así, los estudios naturalistas se desarrollaron en un contexto estatal de tinte utilitarista, ya que se mantuvo la exportación de materias primas rumbo a Europa y Estados Unidos debido a las necesidades económicas de México.

\section{Los niños mexicanos hacia 1870}

La "infancia" en el último tercio del siglo XIX se definió de manera general como el periodo de la vida que comenzaba con el nacimiento y finalizaba en la pubertad. Ésta se dividía en la "primera infancia" que abarcaba de los 0 a los 7 años y la "segunda infancia" que comprendía de los 7 a los 12 ó 14 años. El niño se concibió como el individuo de escaza edad, lenguaje simple, necesidad de protección por parte de sus padres, "buenos" sentimientos, corta estatura, subordinación hacia los adultos, poco desarrollo corporal, interés en el juego, indefensión ante el "mundo" adulto, personalidad "inocente", gran imaginación y un temperamento que necesitaba ser disciplinado. ${ }^{5}$ De ambos periodos 
de la infancia, el segundo se consideró más favorable para la instrucción formal en el aula, iniciar el hábito de la lectura dentro del hogar, fomentar su inserción en la sociedad y ampliar la educación mediante aprendizajes informales o extra escolares (divulgación de la ciencia, deportes y actividades artísticas) con el objetivo de "moldear" positivamente el carácter del futuro ciudadano. ${ }^{6}$

En el Distrito Federal, los niños lectores de las revistas mencionadas iniciaron su educación primaria mediante la novedosa Ley Orgánica de Instrucción Pública de 2 de septiembre de 1867 que reestructuró la instrucción pública de primeras letras y también la superior, bajo la injerencia de la práctica científica. Juárez confió el proyecto de reorganizar la educación en todos los niveles a Antonio Martínez de Castro, secretario de Justicia e Instrucción Pública, quien convocó a una comisión especial conformada por Francisco y José María Díaz Covarrubias, Pedro Contreras Elizalde, Ignacio Alvarado, Eulalio M. Ortega, Leopoldo Río de la Loza, Agustín de Bazán y Caravantes, Antonio de Tagle y Alfonso Herrera. Un mes más tarde y por designación presidencial se unió al grupo Gabino Barreda. A través de estos individuos se estableció una estrecha relación entre el Estado y los grupos científicos de toda índole, especialmente al reconocer por parte del gobierno la importancia de apoyar las actividades de las asociaciones científicas que se formaron entre 1867 y 1880, como la Sociedad Mexicana de Historia Natural (1868), la Sociedad Farmacéutica Mexicana (1871), además de agrupaciones anteriores a estos años como la Sociedad Mexicana de Geografía y Estadística (1833) y la Academia Nacional de Medicina (1864).

A través de dicha ley se dejaron atrás los preceptos del lancasterianismo y se adoptaron los postulados positivistas, con los cuales los liberales mexicanos intentaron formar los cuadros dirigentes de profesionales basados en las nuevas generaciones de jóvenes provenientes de los estratos medio y alto. El plan de estudios para la instrucción primaria de varones que estableció la ley de 1867 se conformó de asignaturas como Lectura y Escritura, Gramática castellana, Estilo epistolar, Urbanidad, Dibujo lineal, Moral, Aritmética, Sistema métrico decimal, Elementos de Física, Artes, Fundamentos de Química y Mecánica prácticas, Nociones de Derecho y Rudimentos de Historia y Geografía con énfasis en México. ${ }^{7}$ Como se aprecia, el gobierno de Juárez basó gran parte de su reforma social en la adquisición de conocimientos científicos que permitieran el desarrollo de las actividades económicas y sociales de los mexicanos.

Otro documento importante dentro del proyecto juarista en el que se expresan las intenciones de desarrollar la ciencia en el país es el Decreto de 14 de enero de 1869. En éste quedaron precisados varios puntos sobre la instrucción pública, como la importancia de la libertad de enseñanza, la necesidad de popularizar y vulgarizar las ciencias exactas y naturales, y el establecimiento de la Escuela de Naturalistas que no llegó a concretarse. Todas las nuevas escuelas de instrucción superior estuvieron proyectadas de acuerdo al positivismo difundido por Barreda y los planes de estudio se basaron en preceptos laicos, enciclopédicos, pragmáticos y progresistas que proporcionarían a todos los estudiantes de cualquier profesión un conjunto común de "verdades científicas".

Ente 1867 y 1875 en varios estados de la república se decretaron leyes que pusieron en práctica el principio de la instrucción pública primaria obligatoria, como la Ley Orgánica de la Enseñanza Primaria del Estado de Morelos (1872), la Ley de Instrucción Pública del Estado de México (1874) y la Ley Orgánica de Instrucción Pública del Estado de Veracruz (1874). ${ }^{8}$ En estos mismos años cobró fuerza entre las clases media y alta de México la convicción de que la infancia y su buena dirección bajo las novedosas leyes de instrucción serían cruciales en la determinación del tipo de adulto en que se transformaría todo niño. Asimismo, se creía que un adulto "útil" era aquél que había sido educado bajo los cánones de la ciencia, pues podría desempeñarse como profesionista, empresario, político o comerciante, dispuesto a poner su formación educativa al servicio de la patria. ${ }^{9}$

En 1870 las escuelas de primeras letras del Distrito Federal sumaban 292 y atendían a una población de 18, 482 alumnos. Desde la ley de 1867 se inició un proceso pedagógico en el cual "se registraron importantes cambios en las maneras de concebir a los educandos, el espacio escolar y el tipo de prácticas en su interior". ${ }^{10}$ Cabe señalar que en esta década no se esperaba que los alumnos asistieran de manera continua al aula y estaba permitido que en cualquier momento del año escolar llegaran nuevos estudiantes sin tener en cuenta su bagaje educativo o lo adelantado del curso. Bajo este contexto, la instrucción informal que brindaban las revistas infantiles cobra especial relevancia 
al tratar de paliar la inasistencia y complementar las lecciones perdidas por este motivo. En efecto, la asistencia de los infantes a la escuela primaria era ocasional a lo largo del año y de acuerdo con Mílada Bazant era de dos terceras partes con respecto a las inscripciones. Los gobiernos municipales y estatales a partir de la década de 1880 pusieron en práctica diversas estrategias para amonestar a los padres de familia cuando los hijos acumulaban varias faltas, ya que la obligatoriedad de la educación apenas se estaba reglamentando. ${ }^{11}$

Los planteles educativos en la década de 1870, de manera general, contaron con algunos salones para clases, un cuarto para el conserje, patio de recreo y en el caso de la asistencia de alumnas había un aula para llevar a cabo las labores "propias de su sexo". Entre el mobiliario destacan pupitres, escritorio para el docente, algún librero, y "otros objetos como cuadros de los héroes de la patria, la campana o timbre de metal que utilizaba el profesor para invocar silencio, el reloj y los pizarrones". ${ }^{12}$

La escuela primaria en estos años cumplió la tarea de difundir entre los pupilos la cultura escrita y el hábito de la lectura dentro de un espacio social que privilegió las asignaturas laicas y científicas. De ahí la importancia del ámbito escolar en el gusto por adquirir revistas infantiles y, a partir de la década de 1880, su unión con los libros dirigidos a los niños y niñas que pretendieron instruirlos en el ámbito de la Historia natural. Con todo esto el espacio de la divulgación de esta ciencia se amplió hacia el final del siglo XIX.13

La divulgación científica unida a la instrucción primaria jugaría el papel de elemento unificador entre las clases media y alta del país al dotar a los infantes de bases "racionales" con las cuales desarrollar el "progreso material" de la república. Precisamente esa base común requería de un medio impreso, en este caso las revistas infantiles, que circulara por todo el territorio nacional y transmitiera el mismo mensaje a todos los lectores.

\section{La prensa infantil en la década de 1870}

En Europa y América desde la década de 1860 las publicaciones periódicas jugaron un papel crucial en el desarrollo del lector infantil, tanto las revistas dirigidas a los niños como a padres de familia y profesores de primaria. Estos impresos periódicos se organizaron bajo una perspectiva secular en la que participaron varios impresores que vieron una oportunidad comercial en los gustos juveniles que fueron cambiando a lo largo del siglo XIX, pues fueron más didácticos y entretenidos, menos "secos" y más coloridos. Todo ello acorde con la escuela y parte de una "misión pedagógica" y moralizante entre estratos medios y altos urbanos, y en menor grado rurales. ${ }^{14}$

También en el último tercio del siglo XIX la Historia natural, en sus vertientes zoológicas y paleontológicas, fue muy atractiva para niños y niñas de estratos medios y altos de Europa y América como lo atestigua la circulación de decenas de revistas dirigidas a este público lector. ${ }^{15}$ Además, esta ciencia era vista como una práctica susceptible de ser llevada a cabo por casi cualquier lector, como los infantes. Al menos en principio cualquiera con capacidades "normales" podía contribuir al avance de los descubrimientos naturalistas como observador, colector, taxidermista, preparador, ilustrador y propagador de especies. Igualmente los pequeños lectores podían adentrarse en el estudio de la naturaleza con tan sólo ir a la montaña, el mar o el jardín de la casa. ${ }^{16}$

Las publicaciones periódicas mexicanas aquí expuestas también estuvieron dentro de un contexto internacional en el que países europeos y americanos vivieron la intensa actividad de la prensa como vía para la divulgación científica. Baste mencionar dos ejemplos: primero una de las revistas más exitosas en el último tercio del siglo XIX en Gran Bretaña titulada Hardwicke's Science Gossip: A Monthly Medium of Interchange and Gossip for Students and Lovers of Nature (1865-1893). Ésta circuló mensualmente y costaba 4 peniques, con lo cual tuvo un precio accesible para muchos lectores, especialmente menores de edad que asistían a las escuelas primarias. Entre sus métodos divulgativos estuvo la inclusión de bellas imágenes alusivas a los textos divulgados. ${ }^{17}$ En segundo lugar se encuentra Popular Science Monthly (1873-hasta la actualidad), revista estadounidense que llegó a cientos de hogares cada mes para satisfacer 
su curiosidad sobre el mundo que habitaban y los avances de la tecnología en todo el mundo bajo un lenguaje cercano a las familias lectoras. ${ }^{18}$

En la República Mexicana fue en el decenio de 1870 cuando las revistas infantiles vivieron un auge, pues aumentó la demanda con respecto a los años anteriores, de manera similar a los contextos europeos y americanos. Además, varias de ellas se publicaron al mismo tiempo y dejaron de ser proyectos editoriales de un par de meses para convertirse en títulos impresos por amplios lapsos de tiempo. La venta de éstas se extendió por varias ciudades del país y las suscripciones tuvieron diversos orígenes geográficos. Estas revistas tuvieron como objetivo satisfacer las inquietudes pedagógicas de las familias educadas y los profesores de primara. ${ }^{19}$ De igual forma se caracterizaron por su eje didáctico y el afán por que los jovencitos gozaran de la lectura instructiva.

La prensa infantil, como la dirigida al público adulto, tuvo una estructura miscelánea que brindó a sus jóvenes lectores una variedad de temas. Entre éstos resaltaron cuestiones históricas, biográficas, de ortografía y redacción; lecturas con contenidos morales y religiosos, además de fábulas, poemas, obras de teatro y cuentos; consejos pedagógicos para los padres, gimnasia, urbanidad y buenas costumbres; y conocimientos útiles de las ciencias como Agricultura, Anatomía, Medicina, Astronomía, Historia natural, Aritmética, Química, Higiene, Física, Geografía, entre otras. La divulgación de la ciencia en las revistas infantiles cobró relevancia en el último tercio del siglo XIX, pues niños y niñas completaban su educación formal mediante la lectura de éstas en el hogar.

En la prensa infantil también se incluyeron gran cantidad de anuncios publicitarios dirigidos a infantes y padres de familia, en especial, de médicos pediatras, instructores particulares, medicinas, juguetes, muebles, libros de primeras letras, ropa, paseos, diversiones urbanas y profesores de diversos conocimientos como lenguas extranjeras o piano. La periodicidad de las revistas varió dependiendo del proyecto editorial, pues algunas de ellas fueron semanales, quincenales o mensuales.

Las revistas infantiles de la ciudad de México a través de la divulgación de los saberes cultos, como la ciencia, trasladó al hogar la cultura "escolar", propia de las aulas, mediante la publicación continua de temas referentes a las asignaturas del plan de estudios establecido en la ley de $1867 .{ }^{20}$ Igualmente, esa divulgación posiblemente palió la inasistencia a la escuela por parte de sus lectorcitos al leer todo tipo de escritos.

De entre todas las ciencias, el conocimiento naturalista abarcó numerosas páginas en las revistas dedicadas a los infantes mexicanos, gracias a que sus redactores estuvieron conscientes de su importancia para el desarrollo económico y social del país al inculcarles el interés por conocer las riquezas naturales de México. Además, ellos tendrían el cometido de concluir el inventario de animales, minerales y plantas que poblaban al país, para que mediante su explotación económica contribuyeran al desarrollo nacional.

En las diversas exposiciones de motivos publicadas en el primer número de cada una de las revistas infantiles destaca el escrito de La Enseñanza titulado "A nuestros lectores" (junio de 1870). En este editorial los redactores afirmaban que la educación popular había llegado a ser en esos años una necesidad urgente, de cuya satisfacción dependía el bienestar de la sociedad mexicana y el porvenir de las generaciones venideras, acorde con los esfuerzos del Estado liberal por ampliar la instrucción entre todos los mexicanos. La publicación recordó a sus lectores que debían vincular los escritos con lo aprendido en su entorno familiar y escolar, pues de esta manera se despertaría su inteligencia con el fin de descubrir el "orden" que encerraba la Naturaleza. ${ }^{21}$ En efecto, una vez que se plantaba la "semilla intelectual" en casa, la escuela de primeras letras brindaría las herramientas para desarrollar la "mente científica" del futuro adulto. Los redactores aseguraban que el tono divulgativo de la Historia natural en esta revista pasaría frecuentemente del estilo grave al festivo y jocoso; endulzarían la amargura y sequedad de las exposiciones científicas revistiéndolas con el "agradable ropaje" de la fábula 0 de la anécdota, más atractivas para los infantes. Así, las lecciones divulgativas se publicarían en varios números consecutivos, con la finalidad de preparar las tiernas inteligencias infantiles para estudios cada vez más arduos y complicados. En efecto, la infancia era el momento del juego y el entretenimiento, "en donde, en ocasiones, se enseñaba a pensar por medio de la diversión, como en el caso de las charadas. Era así como se lograba romper la frontera entre el aprendizaje y la diversión, la cual permitía el desarrollo no sólo de la imaginación, sino también del ingenio infantil" ${ }^{22}$ 
En tono semejante al anterior, los redactores de El Escolar, revista dedicada a las niñas de clase baja, expresaron que éstas, "olvidadas por la fortuna", se verían colocadas "en un precipicio si en su camino no se hubieran interpuesto una sociedad, que con caricias, con halagos, [procuraba] derramar en [sus] corazones el germen de la instrucción". Dicho redactores confiaban en que las lectorcitas comprenderían que ser mujeres instruidas era su única y mayor riqueza. Éstos sabían que eran pobres en lo económico, "pero serían ricas en instrucción y virtud" que durarían toda la vida, en comparación de las riquezas pasajeras y volubles que no aseguraban la felicidad familiar. ${ }^{23}$ En este sentido, el esfuerzo por llevar la instrucción hacia los infantes no fue exclusivo de las clases privilegiadas ni del género masculino, aunque presuponía cierto grado de alfabetización y un "agente" que llevara la revista a los niños pobres o huérfanos.

Como se aprecia, los grupos de redacción de ambas revistas fueron conscientes de que la instrucción era uno de los medios de ascensión social más efectivos entre las clases media y baja, pues una jovencita instruida sería más atractiva para algún profesionista o burócrata que si solamente confiara en su belleza. La prensa para niños también contribuyó a delimitar los ámbitos escolar-formal y hogareño-informal, al designar que sus contenidos estaban basados en el entretenimiento racional, propio del ámbito privado de la familia.

A la par que se publicaron revistas dirigidas al público infantil, en la década de1870 también se dieron a la luz impresos periódicos dirigidos a maestros de instrucción primaria y padres de familia que expusieron las bondades de la instrucción y la necesidad de modernizarla. Por ejemplo, La Voz de la Instrucción (1871) a cargo del maestro Antonio P. Castilla, quien estuvo interesado en debatir sobre las nuevas propuestas pedagógicas que circulaban en América y Europa. Otras revistas editadas en la ciudad de México fueron El Porvenir de la Niñez (1870-1875) y La Enseñanza Objetiva (1879), mientras que en los estados resaltan las publicaciones guanajuatenses tituladas La Escuela de Primeras Letras. Periódico de la Sociedad de Enseñanza Dedicado a los Padres de Familia (1870) de la ciudad de Guanajuato y La Educación (1874) impresa en León. ${ }^{24}$

En tanto que se buscó robustecer la instrucción informal mediante las revistas infantiles de los años 1870, resalta la crítica de las publicaciones arriba mencionadas acerca de concluir lo iniciado con la ley de 1867 y renovar por completo la instrucción primaria. En aquel momento se escucharon numerosas voces interesadas en concientizar a la sociedad mexicana acerca de la importancia de reforzar la educación de los infantes desde la unión de los ámbitos familiar y escolar. ${ }^{25}$

\section{Historia Natural para niños mexicanos}

Los grupos de editores de la prensa infantil de la década de 1870 tuvieron en común el interés por incluir una gama de contenidos sobre la diversidad natural de México y otras zonas del planeta teniendo en cuenta que la mayoría de su público lector entraba en contacto con plantas, rocas y animales en sus horas de juego o en los paseos dominicales que disfrutaban en familia. Asimismo, estos contenidos se vincularon con las clases que los lectorcitos cursaban en la escuela primaria con la finalidad de complementar las "austeras" lecciones del profesor con los "divertidos" escritos brindados por las revistas.

Los temas naturalistas se dividieron en dos grupos: el principal mostró a los lectorcitos la riqueza de los tradicionales reinos que agrupaban a los seres vivos: vegetal, mineral y animal; el segundo se conformó por los "reinos" emergentes como el de microorganismos y fósiles. Lo anterior es un reflejo de la diversidad de objetos de estudios de los naturalistas mexicanos y de su presencia en la cultura científica del público nacional, ya acostumbrado a leerlos en la prensa de adultos desde las primeras décadas del siglo. ${ }^{26}$

A los jóvenes lectores se les explicó que el objeto de la ciencia llamada Historia natural era el estudio de dos tipos de seres: unos dotados de vida, que nacen y mueren después de crecer, y que tienen una forma determinada en su cuerpo tras la asimilación de nuevas moléculas con las que ocupan un lugar determinado en el mundo y, particular- 
mente, cuentan con la facultad de perpetuarse por medio de gametos (células sexuales) que al desarrollarse siguen la misma forma, tales como animales, vegetales y microorganismos; y otros que no tienen vida y, por lo tanto, no mueren y corresponden a los minerales. ${ }^{27}$

Sobre este asunto, en el artículo Los niños y el espectáculo de la Naturaleza se invitaba a los jovencitos a contemplar los paisajes y la diversidad de seres vivos e inertes que se encontraban cercanos a ellos, pues su observación despertaría la imaginación y gusto por la ciencia, ya que el contacto directo con la naturaleza afectaba sus sentidos y formaban "la gran decoración visible en medio del cual vivimos". Así, con las primeras impresiones que recibirían los sentidos corporales podrían diferenciar a las especies del medio que habitan con respecto al aire, luz, sales, agua y la infinita gama de minerales. ${ }^{28}$

En opinión del autor, los contenidos de Historia natural en las revistas infantiles cumplían con la misión de alentar la curiosidad de los niños y, que bien dirigida, fomentaría capacidades científicas como la observación del espectáculo de la naturaleza y la apreciación de sus bellezas; además de la búsqueda racional de las relaciones entre los fenómenos naturales que día a día y de manera constantemente rodeaban al ser humano. ${ }^{29}$ Así, los niños podrían iniciarse, años más tarde, en el estudio científico de los reinos de la naturaleza en alguna institución de instrucción superior.

Asimismo, el autor aseguró que aquel niño que adquiriera el hábito de preguntarse sobre las maravillas botánicas y zoológicas, aseguraba en el futuro un caudal de goces para toda la vida, porque al mantener los hábitos de observación y reflexión lograría con el tiempo el razonamiento necesario para distinguir y estimar "en toda su delicadeza los encantos y bellezas de la naturaleza; la que, para muchos [era] un libro cerrado en que no [sabían] leer una palabra sola; porque no se les enseñó en tiempo oportuno a abrir y hojear ese gran libro". ${ }^{30}$ La insistencia en que los lectores prestaran atención sobre el mundo que los rodeaba se fundaba en que éste era el inicio del método científico. Igualmente el niño daría los primero pasos para pensar científicamente y en su edad adulta descifrara el "libro de la naturaleza", en especial, el "capítulo" sobre las riquezas de México.

Bajo esta premisa, la divulgación científica era una tarea cultural de suma importancia, si se consideraba como el inicio de una vida dentro de las disciplinas científicas, ya que los niños del presente, mañana serian hombres y, en la edad madura, se reflejaría todo lo que hubieran aprendido en sus primero años. Por ello, los jóvenes instruidos en el ámbito científico estaban llamados a ser "los oráculos del saber humano" a través de la sapiencia otorgada por el estudio racional de la naturaleza desde las primeras letras y reforzado en el hogar mediante el "entrenamiento" científico alcanzado en las revistas. ${ }^{31}$

Cabe señalar que los contenidos naturalistas de las revistas mostradas a continuación están orientados hacia una visión universalista de la Naturaleza, es decir, que a los niños mexicanos se presentó la diversidad de vegetales, animales, minerales, fósiles y microorganismos del mundo, y se enfatizó escasamente a las especies nacionales. Esto contrasta con la amplia actividad de los científicos del país al llevar a cabo numerosos estudios sobre las especies nacionales en términos médicos (con la publicación de la Gaceta Médica de México desde 1864), naturalistas (a partir de la edición de La Naturaleza. Periódico de la Sociedad Mexicana de Historia Natural en 1869) y geográficos (mediante la continuación del Boletín de la Sociedad Mexicana de Geografía y Estadística en el decenio de 1870).

\section{Las riquezas del reino vegetal}

La Botánica, rama de la Historia natural, era definida como la ciencia que tiene por objeto el estudio de los vegetales, tanto de pequeñas plantas como de grandes árboles. Dicha especialidad mantiene una clasificación de los grupos que estudio en clases, familias y especies, basada en la distinción por estructura y propiedades particulares de cada ser vivo. ${ }^{32}$ Esta disciplina se consideraba cercana a los niños, pues todos habían convivido con la diversidad florística del país en los jardines caseros, patios escolares, paseos y excursiones al campo y los viajes a huertas y haciendas familiares durante las vacaciones o días feriados. 
Uno de los escritos de mayor extensión sobre cuestiones botánicas fue la serie de lecciones llamadas "Botánica de mi hija" de J. Neraud que se publicaron en La Enseñanza. El tono divulgativo de estas lecciones se centraron en familiarizar a los niños con las distintas familias de plantas mediante ejemplos particulares, como el alcatraz (Arum spp), tan común en los jardines mexicanos. La descripción de la especie fue la siguiente:

[El alcatraz tiene] una hoja de naturaleza particular, llamada espata, se enrolla a modo de cucurucho en derredor de los pistilos y estambres; nacen a éstos sobre un cilindro largo, terminando en figura de maza; los estambres ocupan el piso inferior, los ovarios están colocados encima, y rematan en un penacho de pelos cuyo uso no se averigua todavía; el conjunto de todo esto se llama espádice. Los tales espádices en el momento de la fecundación ofrecen fenómenos curiosos en algunas especies de alcatraz: en primer lugar, se calientan considerablemente, y luego exhalan un hedor a carne corrompida abominable por cierto. ¿Qué tal será, que hasta las moscas verdes, los necróforos y demás insectos que viven habitualmente sobre los animales muertos, se equivocan, y van en enjambres a meterse al cucurucho aquel? $?^{33}$

Algunos de los mencionados insectos al sentirse atraídos por el olor del alcatraz caían en la trampa y al posarse sobre ésta se encogían los pétalos de tal modo, que formaban una "ratonera" de la cual no podían salir. En esta explicación se observa el conocimiento ortodoxo de la Botánica a través de la descripción anatómica, para luego incluir datos amenos, como la relación entre los insectos y el alcatraz, que alentarían la imaginación infantil. Probablemente, los niños que gustaban de las plantas observarían detenidamente los alcatraces de su jardín para constatar lo leído y sacar sus propias conclusiones.

Una segunda serie de lecciones divulgativas publicadas en La Enseñanza fue La planta y su vida. En este escrito se habló a los jóvenes de los elementos químicos necesarios para el crecimiento de las plantas. La narración inició explicando que los botánicos, además de estudiar a la flora en su hábitat, también llevaban a cabo estudios en laboratorios para determinar cómo es que viven las plantas y cómo se alimentan. Por ello, era necesario emprender diversos análisis químicos de las cenizas vegetales para revelar su composición. Tras varios experimentos, los naturalistas del mundo convinieron en que 4 componentes constituían invariablemente a todas las plantas y eran sales solubles, tierra calcárea y magnesia, ácido fosfórico y sílice. ${ }^{34}$ Aunque en varias ocasiones se presentaban sustancias identificadas como minerales provenientes de rocas de las montañas, pero en un estado insoluble y sólo accesible a la planta mediante la erosión.

Presumiblemente, los jovencitos se preguntarían cómo obtenía la planta dichos minerales si estaban en las rocas. La respuesta era que en todo campo de cultivo sometido a la irrigación y sin abono, como los mexicanos, se producía anualmente una gran cantidad de pasto gracias a las sales que llegaban mediante manantiales, ríos subterráneos 0 deslaves en la temporada de lluvias. Mediante estos procesos el agricultor recogía abundantes cosechas de maíz, trigo, frijol, entre otras especies. ${ }^{35}$ Esta descripción de la labor científica de los botánicos tuvo como finalidad revelar al lectorcito que muchos de los elementos naturales que el hombre acostumbra considerar inútiles son imprescindibles para la vida de toda planta. En efecto, las sustancias vegetales que alimentan al ser humano se componen de elementos químicos como carbono, oxígeno, hidrógeno, nitrógeno, fósforo y azufre. Si éstos estuvieran aislados en el ambiente carecerían de utilidad para la planta y no se formaría compuestos de fibrina, albúmina o gluten. Y aunque el almidón, azúcar o ácido cítrico de frutos y verduras se componen de oxígeno, hidrógeno y carbono, la planta no tendría una sola de esas sustancias si le faltasen las sales alcalinas provenientes del suelo.

También en La planta y su vida se trató el tema del gran número de familias botánicas que habitaban tres regiones claramente diferenciadas de México. La primera era la región tropical, llamada coloquialmente como "tierra caliente". Comprendía todo el litoral de los océanos Pacífico y Atlántico y se adentraba a los puertos por medio de canales y pequeñas corrientes. La segunda era la planicie elevada allende las costas y que a pesar de su situación meridional, gozaba de un clima dulce. Se le nombraba "tierra templada". La tercera región se hallaba en medio de cadenas de montañas con un clima frío, cuyo nombre popular era "tierra fría". De esta última zona resaltaba el valle de México, que a excepción de una pequeña parte situada al Este, se termina en las faldas de la cadena volcánica del Popocatépetl y 
el Iztaccíhuatl y "allí es donde en medio de una especie de paraíso, se encuentra México, la capital del país". ${ }^{36}$ En este párrafo se observa el avance en los estudios de la geografía botánica nacional, pues se contaban con una clasificación general que permitía tener mayor claridad en la distribución botánica mexicana, pero en la década de 1870 aún faltaba mucho por hacer.

En el mismo escrito se dieron descripciones de distintas plantas características del país, como los cactus, representantes de las regiones centro y sur. Éstos podían ser grandes o pequeños, y se caracterizaban por su forma redondeada con otras bolas espinosas salientes. Algunos eran de crecimiento longitudinal, ofreciendo largos tallos, delgados, flageliformes, que vegetan parásitos sobre los árboles, como el cacto común de los jardines. ${ }^{37}$ Todos los cactus eran originarios de América y crecían entre los $40^{\circ}$ latitud Norte y los $40^{\circ}$ latitud Sur. Como sabrían los lectorcitos, la mayor parte de ellos requiere de un terreno seco, expuesto a los ardores del sol, lo cual contrastaba con "el jugo acuoso y acidulado" que contienen en abundancia. Esta cualidad los hace preciosos para los sedientos viajeros y con razón habían recibido el nombre de "fuentes del desierto". 38

El anónimo de autor mencionó que muchos de los niños mexicanos habrían probado las tunas o frutos de las cactáceas, pues eran muy demandados en aguas frescas y postres. Otras de sus aplicaciones prácticas se daban en las regiones del norte del país como material de construcción, pues aunque su tallo es suculento con el paso del tiempo siempre se transforma en madera muy sólida. Esto se observaba en los cirios, pues al envejecer se despojan de su corteza presentando su madera blanca y a la distancia parecen espectros. ${ }^{39}$ Los arrieros, comerciantes y viajeros que se veían sorprendidos por la noche en los caminos de estados como Coahuila, Nuevo León, Zacatecas o Durango empleaban los cactus para hacer fuego; defenderse de las picaduras de mosquitos; cocer su pan de maíz; y alumbrarse en las noches. Por este último uso algunas de estas especies se les nombraban "cardos de antorchas". Además, la madera de las cactáceas es en extremo ligera y se transporta fácilmente. Esta mención a las cactáceas mexicanas en relación con las tres regiones botánicas generales es representante de las escasas menciones a la diversidad natural del país que tuvieron a su alcance los niños del decenio de 1870.

De manera general, la divulgación de la Botánica entre los niños y niñas se basó en acercar el conocimiento ortodoxo, como la anatomía, distribución y taxonomía de la flora, mediante un lenguaje sencillo; y presentar ejemplos entretenidos sobre las particularidades de varias plantas, algunas de las cuales se veían cotidianamente en jardines y mercados o los alrededores de sus ciudades.

\section{La variedad del reino animal}

La Zoología también contó con varios artículos de tinte divulgativo en las diferentes revistas para niños de la década de 1870. Algunos escritos ahondaron en el estudio científico de los animales, pero la mayoría de ellos versaron sobre la diversidad de la fauna del mundo, desde los organismos "simples", como los gusanos o insectos, hasta los seres vivos "complejos", como aves y mamíferos. Esta especialidad de la Historia natural fue entendía como el estudio científico de la totalidad de los animales del planeta y contaba con tres ramas: organografía o anatomía, que se ocupa de las partes u órganos que constituyen el ser viviente; fisiología, que enseña las funciones de cada uno de dichos órganos; y por último, taxonomía, entendida como la clasificación y descripción de las diversas especies. ${ }^{41}$ A los lectorcitos se les dijo que los naturalistas habían divido a los animales en cuatro grupos generales para su mejor estudio. Éstos eran: vertebrados, anillados 0 articulados, moluscos y zoofitos, que seguramente conocerían por las lecciones del aula o su vida diaria.

De los cuatro grupos zoológicos, los invertebrados, en especial los marinos, fueron populares en las revistas para niños, tal vez por sus formas tan peculiares, como se observa en "La esponja y el coral". La primera no era un animal muy conocido por los niños de las ciudades, debido a que vivían en los lechos marinos. Por eso, para que estuvieran a su alcance se les describía como seres de formas muy variadas, generalmente como cerebros. Los mares tropicales 
suministraban grandes y hermosas esponjas que se encuentran pegadas a las rocas a poca profundidad. Los artesanos, antes de emplearlas para sus oficios, primero las lavan varias veces para quitarles la materia animal de que están cubiertas y los cuerpos extraños que están adheridos a ellas. El segundo paso es blanquearlas con cloro, para luego dejarlas secar al sol cuando ya están listas para emplearse como esponjas para el baño diario. ${ }^{41}$

El coral era mucho más familiar, sobre todo entre las clases altas, por su uso en la joyería. De este animal marino se decía que era un polípero, es decir, "una república de animalillos" de una estructura sencilla llamada pólipo. Su forma, a simple vista, recuerda a un árbol cuyo tronco está fijo a una roca. Su color es rojo o rosado y en cuanto a su textura es calcárea, pues la superficie ofrece una infinidad de agujeritos en cada uno de los cuales hay un pólipo alojado. ${ }^{42}$ Además, una membrana cubre enteramente el "árbol" y reúne así a todos los animalillos que lo habitan dentro de una comunidad, pues el alimento que toma cada uno lo aprovechan todos. Los buzos encontraban el coral pegado a las rocas, en la posición de un árbol al revés: el tronco hacia arriba y las ramas abajo. ${ }^{43}$ Es probable que algunos de los lectores de este artículo observaran las joyas de coral de sus madres y abuelas, junto con las esponjas utilizadas en el baño diario para constatar la anatomía de la que hablaba el autor.

Los mamíferos fueron los individuos del reino animal con mayor representación en las revistas infantiles, en especial, los de gran tamaño y vida salvaje. De entre éstos, los felinos fueron muy populares, como el tigre, el león o “El lince caracal". A éste se le representaba como un cuadrúpedo originario de Asia y África de gran ferocidad y hábitos carnívoros. Entre sus características se encontraban su mirada penetrante y sagaz para descubrir con facilidad a cualquier presa; color bermejo oscuro salpicado de algunas manchas negras en la parte superior del cuerpo que le dan un aire sombrío; la cola corta y las orejas largas siempre erguidas que a la vista "proporcionan altivez y belleza al conjunto de su fisonomía". En cuanto a sus hábitos, rara vez se le contemplaba en las llanuras o en lugares accesibles al hombre, ya que preferían la espesura de los bosques o las cumbres montañosas, "allí donde la voraz pantera, el sangriento tigre y el altivo león tienen su morada, allí también el lince busca su habitación ordinara". ${ }^{4}$

La mente vivaz de los niños podría despertar su amor por la naturaleza a través de estos ejemplos zoológicos, en especial, al resaltar el carácter del lince como un animal salvaje e indomable, "dotado de una fuerza prodigiosa, de una agilidad admirable, de una viveza peculiar, que persigue con avidez a los pequeños cuadrúpedos como la liebre, el conejo y aún el perro; y sobre todo, a los pájaros que forman su principal alimento". ${ }^{45}$ Los felinos probablemente despertaban la imaginación y curiosidad de niños y niñas por saber más sobre ellos. Además, en muchas de las narraciones de aventuras, la presencia de este tipo de animales era continua y así comprendieran mejor los cuentos y novelas de tipo infantil.

Un animal de mayores dimensiones y aún más exótico para la década de 1870 fue el gorila. De este pariente del hombre se sabían pocas cosas, pues su hábitat se encontraba en el corazón de África. Por ello, insistía el autor, era difícil "que nuestros lectorcitos vean vivo a este terrible animal", ya que ha resultado casi imposible atraparlo debido a lo agreste del medio ambiente en el interior del África ecuatorial donde el calor excesivo aniquila a los europeos. ${ }^{46} \mathrm{Hasta}$ mediados del siglo XIX sólo se conocía "tan terrible animal" por los informes de viajeros y los "sabios" naturalistas que habían explorado el centro africano.

La descripción de este inmenso primate fue incluida en El Correo de los Niños, pues su parecido con el ser humano era evidente y sin duda resultaba llamativo para los lectorcitos. De la descripción física se expuso que cualquier gorila era más alto que un individuo promedio y tiene todo el cuerpo cubierto de pelo negruzco, con excepción de la cara, orejas y manos. Su alimento está compuesto de vegetales, como plantas, nueces y plátanos, propios del hábitat. Del comportamiento resaltaba la fabricación de una especie de hamaca colgante de entre los 3 y 12 metros de altura tras reunir las ramas de la parte más frondosa de cualquier árbol, atándolas con bejucos y vástagos de plantas parásitas. Esta "cama" se forra de yerbas y hojas más anchas de las palmas para prestar comodidad al gorila y sus crías. ${ }^{47}$

Como el gorila es una especie cercana al hombre, no debía asombrar a los lectores que tuviera algunos comportamientos similares a éste, pues el primero también camina en posición casi vertical, con las manos detrás de la cabeza y a veces se le encuentra sentado en su hamaca al lado de la hembra o recostado contra el tronco del árbol que habita a 
manera de reposo tras la jornada laboral. Mientras los adultos descansan, no era extraño observar un comportamiento semejante a los niños humanos, pues las crías "brincan y juegan alrededor" de los padres. Cuando los gorilas sorprenden al observador, toman a sus hijos y se refugian en algún árbol desde donde lo intimidas mediante gritos y gestos como haría cualquier padre de familia amantes de sus hijos. ${ }^{48}$ Así, este artículo muestra los esfuerzos de los editores de $E I$ Correo de los Niños por llevar el conocimiento naturalista de mayor actualidad a su público juvenil mediante estrategias divulgativas como la comparación entre el ser humano y las "bestias" que pueblan el mundo entero.

\section{Los servicios del reino mineral}

En comparación con los temas botánicos y zoológicos, la Mineralogía ocupó muchas menos páginas en las revistas infantiles, pero no por ello, dejó de interesar a los jóvenes lectores. Los temas de este reino de la naturaleza abarcaron principalmente las piedras preciosas, los metales y minerales, y las distintas aleaciones hechas por el hombre. Particularmente, El Correo de los Niños fue la revista que se ocupó más de este tema, como lo atestigua el artículo El Fósforo. Este elemento químico fue presentado por su anónimo autor a través de las características combustibles y su utilidad en la vida diaria. A los niños se les explicó que si el cerillo común existía era a causa del descubrimiento del fósforo, definido como la materia que lo hacía arder, a pesar de hallarse en muy pequeña cantidad en la punta de éste. Pero el autor imaginaba que el público al leer sus palabras se preguntaría ¿qué era exactamente el fósforo? La respuesta fue que era una materia blanda, flexible, con olor semejante al ajo, ubicada en cualquier hueso de animal, incluido el hombre, del cual se podía extraer a través de procesos químicos. ${ }^{49}$

Este mineral se extraía de las cavernas y tras un proceso de purificación que lo limpiaba de otros elementos químicos se formaban con él trozos cilíndricos de cerca de 10 centímetros a manera de pequeñas velas. Era preciso tenerlo sumergido en agua porque de lo contrario se inflamaba él solo, con la consecuencia de incendios imprevistos. El fósforo era muy apreciado al final del siglo XIX, como lo veían los niños en la vida diaria en los cabos de velas o en cerillos para iluminar las casas, pero lo que pudo haberlos sorprendido de este artículo era que este mineral "en la oscuridad, y aún dentro del agua, [daba] una luz blanquecina, igual a la de esos insectos que se ven volar de noche, llamados luciérnagas". 50

Un mineral que tuvo un impulso comercial a partir de los años 1870 fue el llamado amianto. Éste no escapo de la pluma de los articulistas de las revistas infantiles, pues se publicó un artículo al respecto. A los críos se les informó que esta roca no se quema nunca, pero como era de una gran rareza quizás no lo conocieran, ni sabrían de donde extraía ni cómo era. El autor explicó a los infantes que era una de las materias primas más solicitadas por la industria moderna y se estaban estudiando diversas aplicaciones para muchos objetos de uso común. ${ }^{51}$

El amianto es un mineral compuesto de sílice, magnesia y cal. En estado natural se encuentra en fibras similares a crines de caballo, tanto de color blanco como cafés. En cuanto a su textura, a veces se hallaba en fibras suaves y sedosas, y otras duras y ásperas. Justo de estas fibras se elaboraban telas resistentes al fuego, pues lejos de quemarse blanqueaban y adquirían brillo al echarlas al fuego. Algunos gobiernos europeos estaban utilizando tan benéfico mineral para hacer papel incombustible tan útiles en los archivos y papelería de los gobiernos. Además de papel tapiz para paredes de todo tipo de casas que estarían libres del fuego. ${ }^{52}$

Este artículo finalizó explicando que el amianto se encontraba en casi todos los países, pero casi siempre pertenecía a una calidad deleznable y de filamentos quebradizos, por lo que la comercialización era difícil. Sin embargo, la buena calidad de este mineral, compuesto por largas fibras de varios colores, del blanco al pardo oscuro, sólo se hallaba en suficiente cantidad para el comercio en los Alpes italianos, a una altura de muchos miles de metros, lo que complicaba su explotación y venta en todo el mundo. ${ }^{53}$ La descripción de este mineral debió maravillar a los lectorcitos, pues se hablaba de algo que sonaba mágico: un material que no se quemaba. Si bien el amianto se consideró como un mineral posiblemente exitoso para la industria en los años 1870, la realidad es que no tuvo el auge esperado, aunque pudo haber 
inspirado a algunos niños a que en la edad adulta buscaran oportunidades de explotación de recursos mineralógicos aún insospechados en el suelo patrio.

Acerca de las piedras preciosas, apareció el artículo El Diamante en el cual se explicaban, sobre todo, sus características físicas. Primero, se informaba a los jovencitos que éste era el más duro de todos los cuerpos, pues los raya a todos, sin excepción, y no se le podía trabajar más que con sus propios polvos. ${ }^{54}$ De entre todos los pueblos del mundo, los Países Bajos se habían caracterizado por la compra venta de piedras y metales preciosos y no resultaba extraño que ahí se hubiera practicado exitosamente por primera vez el corte de diamantes al flamenco apellidado Bergem hacia mediados del siglo XV.

Como los diamantes eran un lujo en el siglo XIX, los niños tal vez no estarían familiarizados con ellos, por lo que se les describía como cuerpos sin color, pero había algunos de color negro 0 amarillo, llamados jacintos. ${ }^{55}$ Otros muy buscados por las mujeres eran los de tonos verdes o rosas. Su peso se cuenta por quilates; y cada uno de ellos equivale a 212 miligramos. Una variante de los diamantes eran los llamados brillantes, que eran cortes de los primeros a manera que presentaran doble punta, como los engastados en un anillo, y que dejan atravesar completamente la luz; y se llama "rosas" a los diamantes que no tienen doble punta y están llanamente engastados en una chapa.

Los estudios químicos y físicos habían revelado algo sorprendente: el diamante no es más que carbón puro y cristalizado, un producto utilizado cotidianamente en las casas para cocinar o calentar agua para el baño diario. Lo anterior se podía constatar en que a pesar de que esta joya era transparente y dura, y el carbón fuera de color negro y muy frágil, los hermanaban cuestiones de su estructura material que el ojo humano no alcanzaba a percibir, como por ejemplo que el primero arde en el aire como el segundo y despide el mismo gas asfixiante, aunque su combustión es más lenta. Además, el diamante está envuelto siempre en una capa terrosa, que hace muy difícil distinguirle de los demás guijarros. ${ }^{56}$

Como se aprecia en estos artículos, la Mineralogía divulgativa se centró en las características fisicoquímicas de minerales y rocas, sin dejar de lado las curiosidades físicas o la utilidad práctica que formaba parte de la vida cotidiana de los niños y niñas. Asimismo, dada la aridez de los términos mineralógicos, los autores intentaron conjuntar las descripciones fisicoquímicas de los minerales en cuestión con aspectos "maravillosos" de algunos de ellos, como la incombustibilidad, la dureza o el costo de algunos de ellos.

\section{Los reinos emergentes: microorganismos y fósiles}

Durante la segunda mitad del siglo XIX, el avance de la Historia natural amplió su campo de investigación a dos nuevos "reinos": los seres vivos de tiempos pasados o fósiles, y los seres microscópicos. Si bien éstos últimos habían sido descubiertos en el siglo XVII por Anton van Leeuwenhoek a través del microscopio, fue después de 1850 cuando los estudios científicos al respecto cobraron auge entre los naturalistas e interés entre el gran público. Para los niños y niñas de la década de 1870, seguramente les parecería un tema atractivo, pues el reino de lo infinitamente pequeño escapaba a su vista y enriquecía su imaginación. Por ejemplo, varios autores los invitaban a observar en algún microscopio las venas, vasos, nervios, glóbulos sanguíneos, etc., del cuerpo de algún animal. Este instrumento de las Ciencias Naturales ampliaba el tamaño en los animales más pequeños y sencillos como los infusorios, descritos como seres "simples" compuestos de una sustancia homogénea y sin estructura. ${ }^{57}$

El anónimo autor del artículo Los monstruos invisibles. Una excursión a lo invisible, publicado en La Edad Feliz, se acercó a sus lectores de una manera amena y divertida, pues inició diciendo lo siguiente:

Quiero llevarte al país más fantástico que sea posible recorrer; y esto sin obligarte a preparar tus maletas, ni aun a tomar el tren, el carruaje o el paquebote. No creas, sin embargo, que piense en ponerte un báculo 
en la mano para que hagas el camino a pie, [...] solamente te exijo de ti que abras los ojos. iQué digo los ojos! uno sólo es necesario; y puedes cerrar el otro si lo quieres. ${ }^{58}$

Estas palabras alentaban a los niños a observar la vida microscópica y a reflexionar sobre la complejidad de la naturaleza, pues abarcaba desde las gigantescas ballenas hasta las diminutas bacterias, pasando por las bestias y las plantas ya descritas. Asimismo, los microorganismos se encontraban en infinitos lugares, hasta entonces seguramente insospechados por niños y niñas, pues estaban en el aire que se respira, en el agua que se bebe, en los alimentos que se ingieren, los vestidos que protegen y adornan el cuerpo, y en las calles por donde se camina. Así, esos millones de seres vivos que el hombre no percibe comparten la intimidad más completa del hombre, "a veces sin que adviertas tu mismo su presencia". 59

Los seres del reino de lo infinitamente pequeño podían ser observados por otros animales, como un insecto o una araña que ven con sus ojos numerosos "corpúsculos" y "animáculos" que el hombre descubre con el auxilio de una lupa o microscopio. Solamente así se podía percibir el común ácaro del queso, veinte veces más pequeño que la hormiga común..$^{60}$ El autor continuó expresando que antes de que los niños y niñas se embarcaran en el "viaje fantástico" debían conocer el "instrumento maravilloso" que los transportaría en un abrir y cerrar de ojos al mundo de los seres invisibles: el afamado microscopio. ${ }^{61}$ Éste era un objeto casi mágico y estaba compuesto, primeramente de un pequeño

\begin{abstract}
[...] disco de cristal, redondo como una pieza de dos cuartos, hinchado y tripulado en su centro como una gruesa lenteja y límpido como el diamante. [La lente] colocada entre el ojo y el objeto que se mira, la lente percibe los rayos luminosos que se dirigen del punto observado hacia la retina y engañan a ésta mostrándola una imagen impalpable y muy amplificada del objeto; pero si repentinamente se quita la lente, el objeto se muestra verdaderamente en su tamaño natural y se percibe la retina de haber sido juguete de una mistificación [...] La lente de cristal, engarzada en un aro o anillo de madera o de cuerno, lleva el nombre de cristal de aumento o de el más científico de microscopio simple; pero relativamente al microscopio compuesto, el simple agranda muy débilmente los objetos. Para el estudio, debe preferirse el microscopio compuesto ordinario, porque es de más fácil manejo y muestra más limpiamente los objetos. ${ }^{62}$
\end{abstract}

Mediante esta descripción del microscopio, se llevó la más moderna tecnología científica a los jóvenes lectores, quienes en la institución secundaria podrían entrar en contacto con este aparato en sus clases de Historia natural. Los científicos modernos agradecían la invención de tan importante instrumento para el estudio de la naturaleza y a éste se debía el poder sondear las "profundidades de la vida" hasta que faltara la vista, pero ahí aún palpitaría el "corazón" de diminutos habitantes de las "tinieblas".

La otra ciencia emergente que estudiaba a los seres vivos, pero aquéllos de los tiempos prehistóricos, era la Paleontología. Dicha ciencia se había desarrollado de manera científica a los largo del siglo XIX, y para la década de 1870 se encontraba sustentada por varios cientíicos en Europa y Estados Unidos, además de un público interesado en animales que parecían fantásticos. El público mexicano no fue la excepción y, particularmente los niños, se sintieron atraídos por tan interesante tema como hasta el día de hoy. Ejemplo de ello fue la serie de artículos publicados en EI Correo de los Niños bajo el título de El mundo antes del diluvio, en el cual se presentaron cerca de 10 animales prehistóricos. Cabe señalar, que a los pequeños lectores se les explicó que dichas especies habían vivido varios siglos antes de la aparición del hombre y que incluso fueron anteriores al supuesto diluvio bíblico. Posiblemente este argumento más cercano a lo teológico que a lo científico, se debiera a que era más sencillo de explicar que discutir sobre las distintas eras geológicas. Además, aún había algunos partidarios del creacionismo y la teología natural que basaban sus descubrimientos en las explicaciones religiosas sobre la edad del planeta.

El proceso por el cual aparecen y desaparecen las distintas especies que habitan el mundo junto al hombre y aquéllas que se encontraban extintas fue explicado a los niños por una ley fija de la naturaleza en que todo variaba. Así, el planeta había tenido varias transformaciones tras sufrir conmociones violentas y cada día que pasaba iba variando su modo de ser. Una prueba palpable de esto era el hallazgo de gran cantidad de fósiles en todos los continentes. ${ }^{63}$ 
El término era utilizado por los científicos y se refería a los animales sepultados bajo las diferentes capas de la corteza terrestre que pertenecían a especies de otros tiempos. La ciencia que estudiaba a los fósiles se llama Paleontología, palabra derivada del griego y que significa "estudio sobre los seres antiguos".

Como puede verse, en el siglo XIX se entendía por resto fósil únicamente a los animales de gran tamaño, pues el autor afirmaba que casi todos estos seres fueron de una talla descomunal y de fuerzas inimaginables, con lo cual debían causar al hombre "inmensos daños, y serle muy difícil matarlos". bl Dadas las escazas décadas de cientificidad de la Paleontología, aún no se distinguían los restos fósiles prehistóricos de las especies que habían convivido con los primeros seres humanos y que se encontraban extintos.

Así como las especies zoológicas habían surgido y desaparecido con el paso del tiempo, había sucedido algo similar con la superficie terrestre, pues los niños debían imaginar que

[...] todas las partes del globo [habían] estado en otras épocas cubiertas por los mares, y donde ellos están era la tierra. Esto se [probaba], porque se [descubrían] fósiles de peces, conchas, etc., en las más altas montañas, lo que [demostraba] que [habían] estado bajo el agua; y fácilmente se [explicaba] que el mar [hubiera] ido echando tierra sobre la superficie de nuestro globo, y enterrando poco a poco en miles y miles de años, los huesos de los animales antediluvianos [...] Se [sabía] que la Tierra no siempre [había] gozado de la temperatura de hoy, y que además, debido a su movimiento de desviación en los puntos en que hoy [hacía] frío excesivo, hacía antes un calor insufrible. Ahora bien, los animales que sólo podían vivir en climas calientes, al convertirse estos en fríos morían poco a poco, y desparecían las especies. Esto mismo sucedería si, por ejemplo, en África el clima se volviese helado. ${ }^{65}$

Tras la lectura de los artículos de divulgación paleontológica, muchos niños y niñas se habrían preguntado si su ciudad habría sido en otro tiempo un impetuoso mar, un árido desierto o una encumbrada montaña, a diferencia del paisaje presente; y si enormes animales ya extintos vivieron en esos lares al lado de hombres primitivos.

Continuando con la narración, como efecto de los cambios en el nivel del mar y la emergencia de la tierra firme, los restos de animales "antediluvianos" se encontraban diseminados por todas partes del planeta, y ya los lectorcitos habrán admirado los grandes huesos expuestos en el Museo Nacional en la capital del país. ${ }^{6}{ }^{6}$ Los fósiles hasta entonces estudiados habían sido nombrados con los nombres de Mammuth, Mastodonte, Dinoterio, Anaploterio, Paleoterio, Glyptodón, Megaterio, Milodón, Ictiosaurio, Plesiosaurio, Megalosaurio, Iguanodón, Labirinthodón o Pterodáctilo, que correspondían a cuadrúpedos, peces, reptiles y "pájaros".

Uno de los fósiles que más revuelo había causado fue el pterodáctilo, o reptil que volaba, y era considerado como uno de los animales más raros que existieron en otros tiempos. La osamenta había sido hallada a finales del siglo XVIII en Alemania y desde entonces habían tenido lugar diversas controversias entres los sabios, pues tuvieron lugar toda suerte de hipótesis por sus extraños cuerpos. Con el tiempo se llegó a la conclusión de que era un reptil-pájaro de grandes proporciones, que debió residir en los pantanos sobre la actual Holanda. En cuanto a sus características anatómicas, se sabía que las alas estaban formadas por una membrana semejante a la del murciélago; la cabeza, igual a la de un pájaro, se hallaba cubierta de escamas; y el cuerpo revestido por un pellejo duro parecido al sapo. La enorme cabeza, el acerado pico y la fortaleza de los nervios probaban que debía ser un enemigo terrible para cualquier animal terrestre. ${ }^{67}$ El artículo concluía entusiasmando a los jovencitos que se adentraran en esta ciencia, pues en los números subsecuentes el autor seguiría hablando de otros fósiles e incluiría grabados que representaran los más notables y conocidos hasta entonces.

Otro animal prehistórico que seguramente debió impactar la imaginación de los pequeños lectores mexicanos fue el ictiosaurio, un animal que parecía sacado de cuentos maravillosos, pues no existía una especie viva similar que fuera conocida por el hombre. El anónimo autor explicó que los restos fósiles habían sido descubiertos a principios del siglo XIX en las costas inglesas y que tras el estudio de sus restos se había nombrado como el lagarto-pez o ictiosaurio dada sus características anatómicas. Este singular fósil había sido antiguo habitante de los mares primitivos y era de 
dimensiones enormes, pues medía hasta 60 metros de largo. De su cuerpo, resaltaban la cabeza y boca monstruosamente grande. Ésta última tenía cerca de 180 dientes, afilados y fuertes, que eran capaces de despedazar un elefante de una sola pasada. ${ }^{68}$

A través de distintos estudios, los paleontólogos europeos habían llegado a la conclusión de que los ojos abarcaban tres cuartas partes de su circunferencia y estaban dispuestos a modo de telescopio, así es que distinguía objetos enormes distancias. ${ }^{69}$ La Paleontología en la década de 1870 todavía era una ciencia en ciernes, y por ello aún se desconocía mucho de la forma de vida de las especies prehistóricas. En el caso del ictiosaurio, no se sabía aún si había sido un mamífero que, como las ballenas, emergía a la superficie marina para respirar o si era más cercano a los peces a manera del tiburón. Inclusive, algunos naturalistas aseguraban que podía andar tan bien en la tierra como en el agua, cosa que se negó completamente años más tarde.

Tanto el pterodáctilo como el ictiosaurio interesaron al público infantil en cuestiones paleontológicas, a través de la lectura de los diferentes artículos publicados, pues eran animales casi imposibles de existir, pero la ciencia demostraba su realidad. Además, estos temas fomentaron el interés de los jóvenes lectores por el estudio de la Historia natural, y muchos de ellos debieron soñar con hallar nuevas especies prehistóricas y ganarse fama mundial.

\section{Consideraciones finales}

La inclusión de la Historia natural en las revistas para niños y niñas en la década de 1870 continuó con la tradición divulgativa de esta ciencia desde las primeras publicaciones del México independiente. La diferencia es que por primera vez los autores de los escritos naturalistas se preocuparon por utilizar un lenguaje ameno y una narrativa acorde con los tiernos años de los lectores, distanciándose de la retórica utilizada para los adultos. Asimismo, este fomento a la divulgación científica estuvo acorde, de manera general, con los planes esbozados por los gobiernos mexicanos a partir de 1867 en cuanto a la confianza plena en la comunidad científica mexicana y sus acciones en favor de la solución de problemas de orden económico y social. Por ello, era necesario que la sociedad mexicana en el futuro inmediato contara con individuos altamente capacitados e integrados a la vida científico-técnica del país.

El conocimiento naturalista publicado en las revistas analizadas estuvo vinculado íntimamente con el día a día de sus lectores por dos razones. La primera de ellas se basa en las vivencias de los niños y niñas en sus horas recreativas en jardines, parques y paseos por el campo, al lado de su familia, mascotas y animales domésticos. La segunda cuestión está relacionada con los contenidos de las materias cursadas en las escuelas a las que asistían los lectores. En efecto, la divulgación de la Historia natural no se limitó a la lectura de los artículos, pues el entorno en el que vivían los infantes mexicanos de clase media y alta implicó un vínculo con la instrucción y las actividades recreativas.

La popularización de la Botánica en las revistas infantiles brindó los rudimentos necesarios para que los lectores se acercaran a esta rama de la Historia natural de manera descriptiva, amena y sencilla, pero no por ello menos instructiva. En particular, el conocimiento sobre las plantas se basó en aquéllas cercanas a su vida diaria, como las que se encontraban en el jardín del hogar o en los alrededores de sus poblados, donde encontrarían una hermosa diversidad vegetal. Asimismo, hubo un intento por mostrar la actividad científica de investigación, como en el caso de los análisis químicos vegetales que los infantes seguramente desconocían.

La Zoología divulgativa se propuso instruir a los niños y niñas, junto al entretenimiento racional, recurriendo generalmente a las especies más exóticas del mundo, como felinos salvajes y simios africanos, o las singulares especies marinas que tanto habrán despertado la imaginación de sus tiernos años. No hay que dejar de lado que también se describieron y explicaron otros animales de la vida diaria como las mascotas, la fauna nociva de los hogares 0 el ganado. Hay que señalar que mucha de la literatura infantil y juvenil estuvo basada en historias que recurrían a animales como protagonistas o que estaban presentes en la narración como personajes secundarios. En este sentido, 
el conocimiento zoológico se vio reforzado por otro tipo de lecturas comunes en los niños de clases media y alta que necesario analizar.

La Mineralogía, que a primera vista puede ser una rama de la Historia natural más aburrida y distante de los niños, explotó todas aquellas muestras de minerales preciosos, como los diamantes, en los cuales los infantes habrían conocido sus destellos y colores a través de las joyas familiares. Otros minerales se encontraban en la vida diaria a través de objetos comunes como cerillos, carbón para planchas y estufas, metales en utensilios de cocina y, por supuesto, las monedas y llaves. Igualmente, habrían conocido los metales preciosos, sobre todo, en las regiones mineras del país, donde la cultura mineralógica era mayor que en el sureste de México.

La divulgación del estudio de los microorganismos fue una de las grandes innovaciones temáticas en las revistas mexicanas del último tercio del siglo XIX. Este tópico, en principio, demuestra la gran actualidad de este tipo de prensa entre los infantes del país, pues les llevaron hasta sus ojos los más avanzados conocimientos sobre los seres vivos. Además, los informaron acerca de la manera de saber de su existencia, como el uso del microscopio, pero sin el rigor y a ortodoxia de los tecnicismos al recurrir a relatos cercanos a la ciencia ficción. Muchos de ellos llegarían a la instrucción secundaria, como los cursos impartidos en la Escuela Nacional Preparatoria, en la cual entrarían en contacto de manera práctica con estos temas y tal vez recordarían sus lecturas de años atrás.

La inclusión de la Paleontología fue otras de las novedades de la prensa infantil, pues hasta entonces sólo se había abordado de manera anecdótica cuando se hallaba algún resto fósil en México o en el mundo. En el decenio de 1870, los niños y niñas mexicanos tuvieron a su alcance una serie de artículos que les explicó de manera fácil y divertida cuestiones como la existencia de seres vivos remotos, especies distintas a las actuales y nociones sobre el tiempo geológico del planeta. Seguramente, los ictiosaurios y los pterodáctilos habrán incitado a sus jóvenes lectores a averiguar más sobre el tema entres su padres y profesores.

Las publicaciones infantiles de 1880 en adelante mantuvieron la inclusión de contenidos naturalistas de corte divulgativo, entre muchas otras ciencias, que revela la constancia en el interés de niños, padres de familia y profesores de primeras letras con respecto a la instrucción informal dentro del hogar que complementaba lo aprendido en el aula.

Presumiblemente, la gama de escritos naturalistas que se publicaron en las revistas dirigidas a los infantes mexicanos en la década de 1870 habrían captado la atención de varios lectorcitos dentro del hogar y tal vez sembró una inquietud por conocer y comprender las maravillas de la naturaleza de México y el mundo. Dicho público tras concluir sus estudios primarios y cursar el bachillerato, podría haberse inscrito en las escuelas de instrucción superior de la capital del país o de otras ciudades para convertirse en ingenieros, farmacéuticos, agrónomos, veterinarios o naturalistas. Hombres que en su edad adulta al finalizar la década de 1880 ocupó los puestos dirigentes en las agrupaciones, instituciones, escuelas y proyectos estatales encaminados a reconocer, investigar y explotar los recursos naturales de la República Mexicana.

\section{Notas e referências bibliográficas}

Rodrigo Vega y Ortega es maestro en Historia por la Facultad de Filosofía y Letras, Universidad Nacional Autónoma de México (UNAM). Profesor del Colegio de Historia de la Facultad de Filosofía y Letras, Universidad Nacional Autónoma de México. Esta investigación forma parte del proyecto PAPIIT: Naturaleza y territorio en la ciencia mexicana (1768-1914) (Núm. IN 303810), Instituto de Geografía-UNAM, responsable Dra. Luz Fernanda Azuela. Contó con apoyo financiero de la Dirección General de Apoyo al Personal Académico-UNAM. E-mail: rodrigo.vegayortega@hotmail.com.

1 Agradezco el apoyo brindado por la Dra. Luz Fernanda Azuela responsable del proyecto PAPIIT: "Naturaleza y territorio en la ciencia mexicana (1768-1914)", (IN 303810) del Instituto de Geografía-UNAM.

2 REYES, Óscar. Las representaciones de las niñas en los manuales de lectura para mujeres en educación elemental a principios del siglo XX. Boletín del Instituto de Investigaciones Bibliográficas, México, v. X, n. 1-2, p. 65, 2005. 
AZUELA, Luz Fernanda. Tres sociedades científicas en el Porfiriato. Las disciplinas, las instituciones y las relaciones entre la ciencia y el poder. México: Sociedad Mexicana de Historia de la Ciencia y la Tecnología, A. C./Universidad Tecnológica de Nezahualcóyotl/Universidad Nacional Autónoma de México, 1996. p. 76.

4 CUEVAS, Consuelo; GARCÍA MELO, Blanca. La investigación científica coordinada por la Secretaría de Fomento, algunos ejemplos (1853-1914). In: AZUELA, Luz Fernanda Azuela; VEGA Y ORTEGA, Rodrigo (Coord.). La Geografía y las Ciencias Naturales en el siglo XIX mexicano. México: Universidad Nacional Autónoma de México, 2011. p. 85.

5 RAMíREZ, Alberto. La infancia en el distrito de Toluca, Estado de México, durante el siglo XIX. In: PADILLA, Antonio; ARREDONDO, Martha; MARTínEZ, Lucía (Coord.). La infancia en los siglos XIX y XX. Discursos e imágenes, espacios y representaciones. México: Casa Juan Pablos/Universidad Autónoma del Estado de Morelos, 2008. p. 322.

6 CASPARD, Pierre. La infancia, la adolescencia, la juventud: para una economía política de las edades desde la época moderna. In: MARTíNEZ, Lucía Martínez (Coord.). La infancia y la cultura escrita. México: Siglo XXI/Universidad Autónoma del Estado de Morelos, 2001. p. 90.

7 ALVARADO, Lourdes. Ideal contra realidad. La Escuela Nacional Preparatoria, eje del proyecto educativo del gobierno de Juárez. In: HERNÁNDEZ, Héctor; BERDEJO, María del Carmen (Coord.). Los mil rostros de Juárez y del liberalismo mexicano. México: Secretaría de Hacienda y Crédito Público/Universidad Autónoma Metropolitana/Universidad Autónoma "Benito Juárez" de Oaxaca, 2007. p. 280.

8 PADILLA, Antonio. En torno a la construcción de las "regiones educativas" en Morelos, 1871-1910. In: MARTínEZ, Lucía; PADILLA, Antonio (Coord.). Miradas a la historia regional de la educación. México: Universidad Autónoma del Estado de Morelos/Miguel Ángel Porrúa/Consejo Nacional de Ciencia y Tecnología, 2006. p. 218.

9 BAJO, Bajo; BETRÁN, José Luis. Breve historia de la infancia. Madrid: Ediciones Temas de Hoy, 1998. p. 120.

10 GRANJA, Josefina. Contar y clasificar a la infancia. Las categorías de la escolarización en las escuelas primarias de la Ciudad de México 1870-1930. Revista Mexicana de Investigación Educativa, México, v. XIV, n. 40, p. 219, 2009.

11 BAZANT, Mílada. En busca de la modernidad. Procesos educativos en el Estado de México 1873-1912. México: El Colegio Mexiquense, A. C./El Colegio de Michoacán, 2002. p. 82.

12 Ibid., p. 138.

13 MARTínEZ, Martínez. Paseando con la ciencia: los libros de `lecciones de cosas', 1889-1921. In: GALVÁN, Luz Elena; MARTínEZ, Lucía (Coord.). Las disciplinas escolares y sus libros. México: Universidad Autónoma del Estado de Morelos/Casa Juan Pablos, 2010. p. 188-190.

14 NOAKES, Richard. The Boy's own Paper and late-Victorian juvenile magazines. In: CANTOR, Geoffrey, et al. (Ed.). Science in the nineteenth-century periodical. Cambridge: Cambridge University Press, 2004. p. 171.

15 FYFE, Aileen; LIGHTMAN, Bernard. Science in the market place: An introduction. In: FYFE, Aileen; LIGHTMAN, Bernard (Ed.). Science in the market place. Nineteenth-century sites and experiences. Chicago: The University of Chicago Press, 2007. p. 211.

16 DROUINAND, Jean Marc; BENSAUDE-VINCENT, Bernadette. Nature for the people. In: JARDINE, Nick; SECORD, James; SPARY, Emma (Ed.). Cultures of Natural History. Cambridge: Cambridge University Press, 2000. p. 408.

17 KNIGHT, David. Public understanding of Science. A history of communicating scientific ideas. New York: Routledge, 2006. p. 150.

18 DAWSON, Gowan. The review of reviews and the new journalism in late-Victorian Britain. In: CANTOR, Geoffrey; DAWSON, Gowan; GRAEME, Gooday; NOAKES, Richard; SHUTTLEWORTH, Sally; TOPHAM, Jonathan R. Science in the nineteenth-century periodical. Cambridge: Cambridge University Press, 2007. p. 178.

19 GALVÁN, Luz Elena. La niñez desvalida. El discurso de la prensa infantil del siglo XIX. In: PADILLA, Antonio; ARREDONDO, Martha; MARTínEZ, Lucía (Coord.). La infancia en los siglos XIX y XX. Discursos e imágenes, espacios y representaciones. México: Casa Juan Pablos/Universidad Autónoma del Estado de Morelos, 2008. p. 171.

20 GALVÁN, Luz Elena. Aprendizaje de nuevos saberes a través de la prensa infantil del siglo XIX. Revista Mexicana de Investigación Educativa, México, v. V, n. 10, p. 297, 2000.

21 REDACTORES. A nuestros lectores. La Enseñanza. Revista Americana de Instrucción y Recreo Dedicada a la Juventud, México, v. I, n. 1, p. 1, 1870.

22 GALVÁN, op. cit., p. 298

23 REDACTORES. A las alumnas de las escuelas lancasterianas. El Escolar. Periódico Dedicado a las Niñas de las Escuelas Lancasterianas, México, v. I, n. 2, p. 1, 1872.

24 GALVÁN, Juan Pedro. La prensa pedagógica (1871-1901). Indicios de un nuevo discurso. Monografia (Licenciatura em História)- México, 2009.

25 Ibid., p. 72.

26 AZUELA, Luz Fernanda. El régimen de cientificidad en las publicaciones del último tercio del siglo XIX. In: LÉRTORA, Celina (Coord.). Geografía e Historia natural: hacia una historia comparada. Estudio a través de Argentina, México, Costa Rica y Paraguay. Buenos Aires: Fundación para el Estudio del Pensamiento Argentino e Iberoamericano, 2010. p. 109-111.

27 HISTORIA Natural. La Enseñanza. Revista Americana de Instrucción y Recreo Dedicada a la Juventud. México, v. III, n. 20, p. 318, 1875.

28 LOS NIÑNS y el espectáculo de la naturaleza. El Ángel de la Guarda. Semanario de los Niños, México, v. II, n. 5, p. 18, 1871.

29 Ibid., p. 18.

30 Ibid., p. 19.

31 Ibid., p. 19.

32 NOCIONES sobre las Ciencias y las Artes. III. El Obrero del Porvenir. Semanario para la Niñez Desvalida. México, v. I, n. 5, p. $20,1870$.

33 NERAUD, J. Botánica de mi hija. Lección XVIII. Familia de las aroidéas. La Enseñanza. Revista Americana de Instrucción y Recreo Dedicada a la Juventud, México, v. III, n. 1, p. 9, 1874. 
LA PLANTA y su vida. Lecciones populares de Botánica. Lección Novena. La Enseñanza. Revista Americana de Instrucción y Recreo Dedicada a la Juventud, México, v. III, n. 3, p. 42, 1874.

35

Ibid., p. 43.

LA PLANTA y su vida. Lecciones populares de botánica. Lección Décima. La Enseñanza. Revista Americana de Instrucción y Recreo Dedicada a la Juventud, México, v. III, n. 6, p. 88, 1874.

37

Ibid., p. 90.

Ibid., p. 90.

Ibid., p. 90

Z00LOGíA y Botánica. La Enseñanza. Revista Americana de Instrucción y Recreo Dedicada a la Juventud, México, v. III, n. 14, p. 223, 1875.

LA ESPONJA y el coral. El Correo de los Niños. Semanario Dedicado a la Infancia Mexicana, México, v. VI, n. 22, p. 86, 1878.

Ibid., p. 86

Ibid., p. 87.

44

EL LINCE caracal. El Ángel de la Guarda. Semanario de los Niños, México, v. II, n. 17, p. 68, 1871.

Ibid., p. 68.

EL GORILA. El Correo de los Niños. Semanario Dedicado a la Infancia Mexicana, México, v. VI, n. 12, p. 46, 1878.

bid., p. 46.

Ibid., p. 46.

EL FÓSFORO. El Correo de los Niños. Semanario Dedicado a la Infancia Mexicana, México, v. V. n. 13, p. 49, 1877.

Ibid., p. 49.

EL AMIANTO. El Correo de los Niños. Semanario Dedicado a la Infancia Mexicana, México, v. V, n. 18, p. 70, 1877.

Ibid., p. 70.

Ibid., p. 70.

EL DIAMANTE. El Correo de los Niños. Semanario Dedicado a la Infancia Mexicana, México, v. VI, n. 20, p. 78, 1878.

Ibid., p. 78.

Ibid., p. 78.

HISTORIA, op. cit., 1875, p. 318.

58 LOS MONSTRUOS invisibles. Primera parte. Una excursión a lo invisible. La Edad Feliz. Semanario Dedicado a los Niños y a las Madres de Familia, México, v. I, n. 7, p. 1, 1873.

Ibid., p. 2.

60 Ibid., p. 2.

61 LOS MONSTRUOS invisibles. Segunda parte. Una excursión a lo invisible. La Edad Feliz. Semanario Dedicado a los Niños y a las Madres de Familia, México, v. I, n. 8, p. 1, 1873.

62 Ibid., p. 1.

63 EL MUNDO antes del diluvio. El Pterodáctilo. El Correo de los Niños. Semanario Dedicado a la Infancia Mexicana, México, v. V, n. 1, p. 1, 1877.

64 Ibid., p. 1.

65 Ibid., p. 1.

66 Ibid., p. 1.

67 Ibid, p. 1.

68 EL MUNDO antes del diluvio. El Ictiosaurio. El Correo de los Niños. Semanario Dedicado a la Infancia Mexicana, México, v. V. n. 6, p. 21, 1877.

69 Ibid., p. 21

[Recebido em fevereiro de 2012, aprovado para publicação em março de 2012] 